\title{
Asymmetrical deposition and modification of histone H3 variants are essential for zygote development
}

\author{
Machika Kawamura, Satoshi Funaya, Kenta Sugie, Masataka G Suzuki, Fugaku Aoki
}

\begin{abstract}
The pericentromeric heterochromatin of one-cell embryos forms a unique, ring-like structure around the nucleolar precursor body, which is absent in somatic cells. Here, we found that the histone $\mathrm{H} 3$ variants H3.1 and/or H3.2 (H3.1/H3.2) were localized asymmetrically between the male and female perinucleolar regions of the one-cell embryos; moreover, asymmetrical histone localization influenced DNA replication timing. The nuclear deposition of $\mathrm{H3.1/3.2}$ in onecell embryos was low relative to other preimplantation stages because of reduced H3.1/3.2 mRNA expression and incorporation efficiency. The forced incorporation of H3.1/3.2 into the pronuclei of one-cell embryos triggered a delay in DNA replication, leading to developmental failure. Methylation of lysine residue 27 (H3K27me3) of the deposited $\mathrm{H} 3.1 / 3.2$ in the paternal perinucleolar region caused this delay in DNA replication. These results suggest that reduced $\mathrm{H} 3.1 / 3.2$ in the paternal perinucleolar region is essential for controlled DNA replication and preimplantation development. The nuclear deposition of $\mathrm{H} 3.1 / 3.2$ is presumably maintained at a low level to avoid the detrimental effect of K27me3 methylation on DNA replication in the paternal perinucleolar region.
\end{abstract}

DOI 10.26508/lsa.202101102 | Received 21 April 2021 | Revised 14 June 2021 | Accepted 15 June 2021 | Published online 24 June 2021

\section{Introduction}

Heterochromatin, which is defined as transcriptionally inert and condensed chromatin, is heavily involved in the regulation of cellular processes such as gene expression, mitosis, and DNA replication (Campos \& Reinberg, 2009; Saksouk et al, 2015). Constitutive heterochromatin is relatively gene-poor and mainly composed of tandem satellite repeats. It is present in the pericentromeric, telomeric, and ribosomal regions of all cell types (Saksouk et al, 2015). Pericentromeric heterochromatin can be identified microscopically as foci within the nuclear region that is densely stained with 4',6-diamidino-2-phenylindole (DAPI). In these regions, satellite repeats are transcriptionally silenced and DNA is late-replicating at the S phase (O'Keefe et al, 1992; Probst \& Almouzni, 2011; Saksouk et al, 2015). However, the characteristics of pericentromeric heterochromatin differ in one-cell-stage embryos, where it forms a ring-like structure around the nucleolar precursor body; this is referred to as the perinucleolar region (Akiyama et al, 2011). Here, the satellite repeats are actively transcribed, and the timing and sequence of DNA replication differ from those aspects in somatic cells (O'Keefe et al, 1992; Ferreira \& Carmo-Fonseca, 1997; Aoki \& Schultz, 1999). Notably, temporal differences in cellular processes between maternal and paternal pronuclei have been observed in the perinucleolar region. Transcriptional activity of satellite repeats is higher and DNA replication is completed earlier, in paternal pericentromeric heterochromatin than in maternal heterochromatin (Aoki \& Schultz, 1999; Puschendorf et al, 2008; Probst et al, 2010; Santenard et al, 2010). These differences suggest that the chromatin structure of the paternal perinucleolar region forms a looser chromatin structure, compared with the maternal perinucleolar region. However, the mechanisms driving the structural and process-related differences between parental nuclei in pericentromeric heterochromatin have not been well characterized.

Recent studies have revealed epigenetic asymmetry between the maternal and paternal pronuclei. Pericentromeric heterochromatin is similar between the maternal perinucleolar region and somatic cells, such that it contains histone $\mathrm{H} 3 \mathrm{di} /$ trimethylated at lysine 9 (H3K9me2/3) and H4 trimethylated at lysine 20 (H4K20me3) (Lepikhov \& Walter, 2004; Santos et al, 2005; Probst et al, 2007; Puschendorf et al, 2008). However, the pericentromeric heterochromatin in the paternal pronucleus lacks these typical heterochromatin modifications (Probst et al, 2010); instead, it contains $\mathrm{H} 3$ trimethylated at lysine 27 (H3K27me3) and H2A ubiquitylated at lysine 119 (H2AK119ub) (Puschendorf et al, 2008; Tardat et al, 2015; Eckersley-Maslin et al, 2018). In addition, heterochromatin protein 1 is recruited to the maternal perinucleolar region, whereas polycomb repression complexes 1 and 2 regulate the paternal perinucleolar region (Tardat et al, 2015). However, the contribution of these epigenetic factors to the asymmetry of cellular processes between parental pericentromeric regions has not been assessed thus far.

Histone variants are key factors determining chromatin structure. Several recent studies have focused on histone $\mathrm{H} 3$ variants, which share highly similar amino acid sequences but display distinctive characteristics and functions. In mammals, there are three non-centromeric histone variants: H3.1, H3.2, and H3.3 (Hake \& Allis, 2006). H3.1 and H3.2 are expressed and incorporated into chromatin in a DNA replication-dependent manner (Tagami et al,

Department of Integrated Biosciences, Graduate School of Frontier Sciences, The University of Tokyo, Kashiwa, Japan

Correspondence: aokif@edu.k.u-tokyo.ac.jp 
2004; Hake \& Allis, 2006). As revealed by ChIP-seq analyses using FLAG-tagged histone variants expressed in embryonic stem cells, H3.1 and H3.2 are generally deposited in both euchromatin and heterochromatin (Yukawa et al, 2014). H3.3 is expressed and incorporated into chromatin in a DNA replication-independent manner (Hake \& Allis, 2006). H3.3 is generally incorporated into euchromatic regions. However, it has recently been revealed that H3.3 also localizes to pericentromeric repeats (Rapkin et al, 2015), suggesting that $\mathrm{H} 3.3$ can be incorporated into heterochromatin. In one-cell embryos, H3.3 is incorporated in the paternal perinucleolar region by the recruitment of DAXX, a chaperone of $\mathrm{H} 3.3$, which is mediated by PRC1 containing SUMOylated CBX2 (Santenard et al, 2010; Liu et al, 2020). This H3.3 incorporation in the paternal perinucleolar region is suggested to regulate the transcription of major satellite repeats (Santenard et al, 2010) and the formation of compact heterochromatin (Liu et al, 2020). Therefore, H3.1, H3.2, and H3.3 have distinct characteristics and mechanisms of chromatin incorporation; they may contribute to regulation of cellular process asymmetry that occurs in parental perinucleolar regions.

In this study, we investigated the involvement of histone $\mathrm{H} 3$ variants in structural and cellular process asymmetry in the pericentromeric heterochromatin between the parental genomes of mouse embryos at the one-cell stage. We found that $\mathrm{H} 3$ variants were localized asymmetrically between the maternal and paternal perinucleolar regions. The maternal and paternal perinucleolar regions were enriched in $\mathrm{H} 3.1 / 2$ with $\mathrm{K} 9 \mathrm{me} 2 / 3$ (H3.1/2K9me2/3) and H3.3 with K27me3 (H3.3K27me3), respectively. The forced incorporation of $\mathrm{H} 3.1$ and $\mathrm{H} 3.2$ into the paternal pronucleus caused an increase in $\mathrm{H} 3.1 / 2 \mathrm{~K} 27 \mathrm{me} 3$ and a delay in DNA replication in the perinucleolar region, leading to developmental failure. These results suggest that the nuclear configuration of $\mathrm{H} 3$ variants causes the asymmetric chromatin structure in parental pronuclei, and that reduced $\mathrm{H} 3.1 / 2$ nuclear deposition in the paternal perinucleolar region prevents accumulation of $\mathrm{H} 3.1 / 2 \mathrm{~K} 27 \mathrm{me} 3$ modification, which has a detrimental effect on DNA replication.

\section{Results}

\section{Nuclear deposition of histone H3 variants in preimplantation embryos}

Using immunocytochemical techniques, we investigated the nuclear deposition of $\mathrm{H} 3$ variants using antibodies that recognize both H3.1 and H3.2 (H3.1/2), or H3.3. The former antibody does not discriminate between $\mathrm{H} 3.1$ and $\mathrm{H} 3$.2. The specificity of the antibodies used was verified by antigen peptide adsorption (Fig S1). The H3.3 signal was clearly detected in the nuclei throughout each stage of preimplantation development (Fig 1A), which was consistent with previous reports (Torres-Padilla et al, 2006; Akiyama et al, 2011). However, the H3.1/2 signal was nearly absent in the pronuclei of one-cell embryos. H3.1/2 was detected in the nuclei of two-cellstage embryos; the H3.1/2 signal increased at the four-cell stage. Inhibition of DNA replication by treatment of embryos with aphidicolin prevented the nuclear deposition of $\mathrm{H} 3.1 / 2$ in two-cell-stage embryos (Fig S2A), indicating that H3.1/2 is deposited into chromatin in a DNA replication-dependent manner during the two-cell stage, as in somatic cells (Tagami et al, 2004).

Although H3.1/2 was not detected in the pronuclei of one-cell embryos in the initial observation, it was clearly visible when the confocal laser scanning microscope detector gain was enhanced (Fig 1B). The pronuclear deposition of $\mathrm{H} 3.1 / 2$ is also DNA replicationdependent at both one-cell and two-cell stages because treatment with aphidicolin inhibited their H3.1/2 signals (Fig S2A and B). Notably, the patterns of $\mathrm{H} 3.1 / 2$ localization differed between parental pronuclei. Although the signal intensity of $\mathrm{H} 3.1 / 2$ was similar between the two pronuclei in the nucleoplasm, the signal was more intense in the perinucleolar region of the maternal pronucleus than in the paternal perinucleolar region. These results suggest that the composition of histone variants constituting pericentromeric heterochromatin differs between maternal and paternal pronuclei because the pericentromeric heterochromatin is localized to the rim of pronucleoli at the one-cell stage (Ferreira \& Carmo-Fonseca, 1997; Akiyama et al, 2011). Previous reports showed that from the late twocell stage onwards, pericentromeric heterochromatin forms chromocenters, which appear under the microscope as foci of high DNA density (Martin et al, 2006). H3.1/2 colocalized with these chromocenters in two-cell-stage embryos (Fig 1C), which suggested that H3.1/2 is involved in the formation of pericentromeric heterochromatin in early preimplantation embryos.

\section{Limited H3.1/2 nuclear deposition in one-cell embryos is caused by low H3.1/2 mRNA expression and incorporation efficiency}

There are two possible mechanisms that cause the limited nuclear deposition of H3.1/2 in one-cell embryos: Low H3.1/2 expression and/or reduced incorporation efficiency of $\mathrm{H} 3.1 / 2$ into chromatin. To identify which mechanism participates in this process, we analyzed the mRNA levels of H3.1, H3.2, and H3.3 using previously published RNA-seq data (Abe et al, 2015). Histone $\mathrm{H} 3$ variants are encoded by multiple genes. In mice, H3.1, H3.2, and H3.3 are encoded by four, eight, and two genes, respectively (Wang et al., 1996a, 1996b; Tang et al, 2015). The reads per kilobase of exon per million mapped reads (RPKM) values for each gene were added to calculate the total RPKM value for each $\mathrm{H} 3$ variant. The RPKM value of $\mathrm{H} 3.3$ at the one-cell stage was normalized to 1 and the relative RPKM values for $\mathrm{H} 3.1 / 2$ variants were calculated (Fig 2A). In the stages at which $\mathrm{H} 3.1 / 2$ nuclear deposition was clearly detected (i.e., two-cell stage onwards; Fig 1A), the relative RPKM values for $\mathrm{H} 3.1$ and $\mathrm{H} 3.2$ were equivalent to (or higher than) the relative RPKM value of $\mathrm{H} 3.3$. However, at the one-cell stage, in which the level of H3.1/2 nuclear localization was low, the relative RPKM value of $\mathrm{H} 3.1 / 2$ was lower than the relative RPKM value of $\mathrm{H} 3$.3. These results suggested that low levels of $\mathrm{H} 3.1 / 2$ mRNA contribute to reduced pronuclear $\mathrm{H} 3.1 / 2$ deposition at the one-cell stage.

To compare the incorporation efficiencies of $\mathrm{H} 3.1$ and $\mathrm{H} 3.2$ relative to H3.3, C-terminally FLAG-tagged cRNA encoding H3.1, H3.2, or H3.3 was microinjected into metaphase II (MII)-stage oocytes at various concentrations $(3,10,30$, and $100 \mathrm{ng} / \mu \mathrm{l})$. The oocytes were inseminated and collected for immunocytochemical analysis with an anti-FLAG antibody at $11 \mathrm{~h}$ post-insemination (hpi). Quantification of anti-FLAG signal intensities revealed that the incorporation efficiencies of H3.1 and H3.2 were significantly lower than those of $\mathrm{H} 3.3$ at cRNA concentrations of $\leq 30$ $\mathrm{ng} / \mu \mathrm{l}$ (Fig 2B). Notably, the incorporation efficiencies of the three $\mathrm{H} 3$ 
A $\alpha \mathrm{H} 3.1 / \mathrm{H} 3.2$
DNA
Merge \begin{tabular}{l|l|} 
1-cell & 2-cell \\
\hline 오 &
\end{tabular}

4-cel

\begin{tabular}{ll|}
0 & 0 \\
0 & 0 \\
\hline 0 & 0 \\
0 & 0 \\
\hline & 0 \\
0 & 0 \\
0 & 0
\end{tabular}
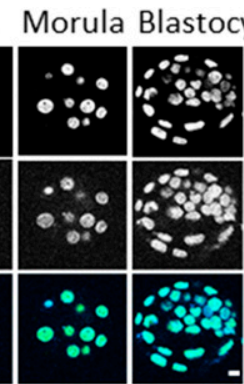

$\alpha \mathrm{H} 3.3$

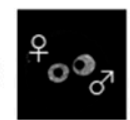

DNA
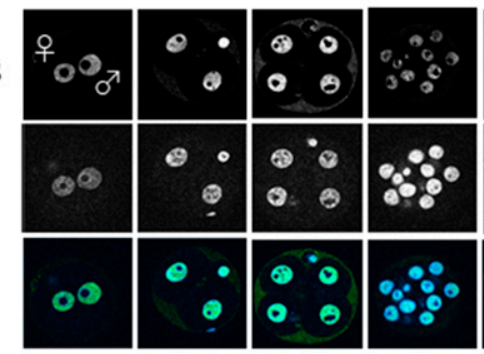

B

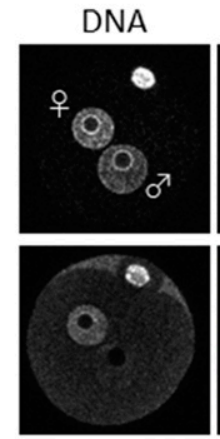

H3K9me3

C
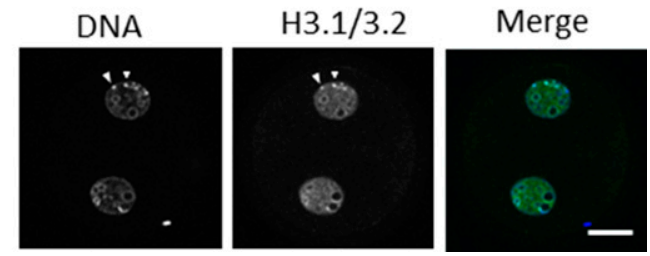

Figure 1. Nuclear deposition of histone $\mathrm{H} 3$ variants in mouse preimplantation embryos.

(A) One-cell, two-cell, four-cell, morula, and blastocyst-stage embryos were immunostained using anti-H3.1/2 (top half) and anti-H3.3 (bottom half) antibodies. Four to five independent experiments were performed. 8-15 embryos were observed for each developmental stage in each experiment; 39-64 embryos were analyzed in total. Representative images are shown for each experiment. Scale bar, $10 \mu \mathrm{m}$. (B) Enlarged images of stained one-cell embryos with enhanced confocal detector gain. In addition to H3.1/2, H3K9me3 was immunostained to discriminate the male and female pronucleus. In the merged panel, blue, green, and red colors represent the signals of DNA, H3.1/2, and H3K9me3, respectively. Scale bar, $20 \mu \mathrm{m}$. (c) Enlarged images of two-cell embryos; arrowheads indicate chromocenters. In the merged panel, blue and green colors represent the signals of DNA and $\mathrm{H3} .1 / 2$, respectively. Scale bar, $20 \mu \mathrm{m}$.

variants were similar when $100 \mathrm{ng} / \mu \mathrm{l}$ cRNA was microinjected. These findings indicate that the relatively low nuclear localization of $\mathrm{H} 3.1$ and $\mathrm{H} 3.2$ in one-cell embryos is caused by both reduced H3.1/2 mRNA expression and low incorporation efficiency into chromatin, relative to $\mathrm{H} 3.3$.

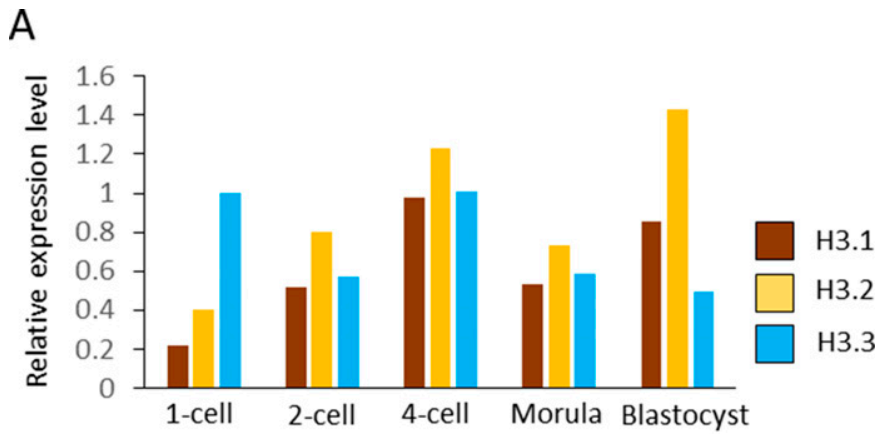

B
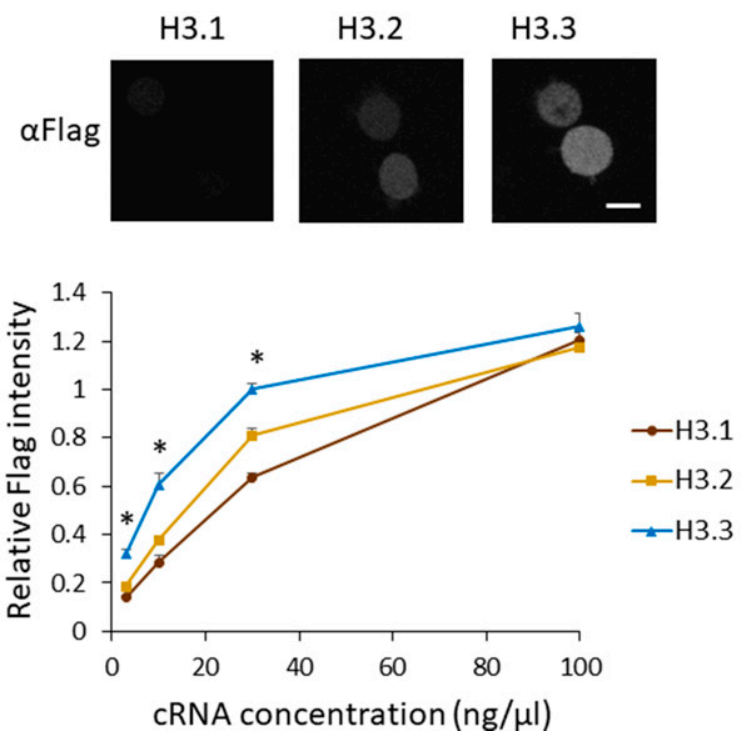

Figure 2. Nuclear localization of H3.1/2 is regulated by mRNA levels and histone incorporation efficiency in one-cell-stage embryos.

(A) mRNA expression levels of $\mathrm{H} 3$ variants during preimplantation development. RPKM values were obtained from previously published RNA-seq data (Abe et al, 2015). RPKM values for each gene encoding H3.1, H3.2, or H3.3 were totaled; the total RPKM of H3.3 at the one-cell stage was normalized to 1. (B) The incorporation efficiency of histone $\mathrm{H} 3$ variants into chromatin of one-cell embryos. Approximately 10 pl of H3.1, H3.2, or H3.3-FLAG cRNA was microinjected into MIIstage oocytes at various concentrations $(3,10,30$, and $100 \mathrm{ng} / \mu \mathrm{l})$. After insemination, embryos were collected at $11 \mathrm{~h}$ post-insemination (hpi) and subjected to immunostaining. Anti-FLAG antibody was used to detect FLAGtagged histones incorporated into chromatin. Representative

immunocytochemistry images depict one-cell embryos, in which $10 \mathrm{ng} / \mu \mathrm{l}$ of H3.1, H3.2, or H3.3-FLAG was microinjected. Scale bar, $10 \mu \mathrm{m}$. The incorporation efficiency of $\mathrm{H} 3$ variants at one-cell embryos is shown as a line graph. The signal intensity for $\mathrm{H} 3.3$ microinjected at $30 \mathrm{ng} / \mu \mathrm{l}$ concentration was normalized to 1 . Nine experiments were performed in total, using $\mathrm{H} 3.3$ injected with $30 \mathrm{ng} / \mathrm{\mu l}$ as a control for each experiment. Three to four experiments were performed for each concentration. Ninety 1-cell embryos were analyzed for the $\mathrm{H} 3.330 \mathrm{ng} / \mu \mathrm{l}$ concentration. For embryos microinjected with other cRNA concentrations, 26-43 embryos were analyzed in total. Bars indicate standard error. Asterisks indicate that the value for $\mathrm{H} 3.3$ was significantly higher than both values of H3.1 and $\mathrm{H} 3.2(P<0.01$ by $t$ test).

Biological significance of limited $\mathrm{H} 3.1 / 2$ nuclear deposition in one-cell embryos

To examine the biological significance of the low $\mathrm{H} 3.1 / 2$ levels in one-cell embryos, we forced the incorporation of $\mathrm{H} 3.1 / 2$ into 


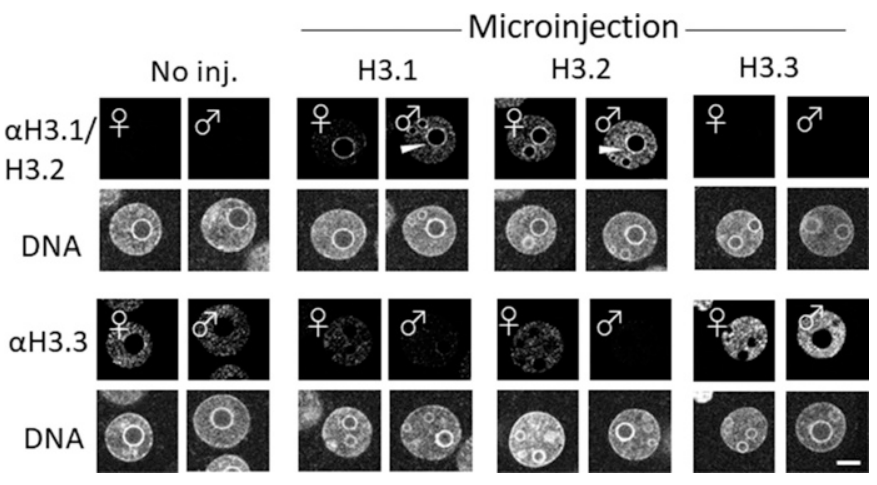

Figure 3. Fluorescence images depicting the effects of $\mathrm{H3.1/2}$ and $\mathrm{H3.3}$ overexpression on $\mathrm{H} 3$ variant nuclear localization in one-cell embryos.

Noninjected control, H3.1-, H3.2-, and H3.3-overexpressing one-cell embryos at $11 \mathrm{~h}$ post-insemination (hpi) were fixed and examined for changes in the nuclear localization of $\mathrm{H} 3.1 / 2$ and $\mathrm{H} 3.3$, using anti-H3.1/2 and anti-H3.3 antibodies, respectively. Eight independent experiments were performed and 39-58 total embryos were examined. Representative images are shown for each experiment. White arrowheads indicate the presence of $\mathrm{H} 3.1 / 2$ in the perinucleolar region of the paternal pronuclei. Scale bar, $10 \mu \mathrm{m}$.

chromatin and analyzed its effect on preimplantation development. Our results suggested that the incorporation efficiency of $\mathrm{H} 3.1$ and H3.2 into one-cell embryonic chromatin was low, compared to the incorporation efficiency of $\mathrm{H} 3.3$ (Fig 2B). However, when a high concentration of cRNA (100 $\mathrm{ng} / \mu \mathrm{l})$ was microinjected into MII-stage oocytes, similar levels of incorporation for all three $\mathrm{H} 3$ variants were observed. Exploiting this phenomenon, we microinjected $100 \mathrm{ng} / \mu \mathrm{l}$ of CRNA encoding FLAG-tagged $\mathrm{H} 3$ variants to force one-cell embryos to incorporate the $\mathrm{H} 3$ variants into chromatin. Less than $20 \%$ of the onecell embryos that had been microinjected with H3.1 or H3.2 cRNA cleaved to the two-cell stage; in contrast, $>90 \%$ of embryos injected with H3.3 CRNA, as well as control embryos (noninjected and GFP CRNA injected), progressed to the two-cell stage (Fig S3).

To exclude the possibility that the additional amino acids introduced with the FLAG-tag were detrimental with respect to embryonic development, we microinjected CRNA encoding H3 variants without the FLAG-tag. We first examined the nuclear localization of $\mathrm{H} 3$ variants in microinjected embryos by immunostaining with anti-H3.1/2 and anti-H3.3 antibodies (Fig 3). The results showed that the level of H3.1/2 nuclear deposition increased in both maternal and paternal pronuclei of H3.1- and H3.2-overexpressing embryos (H3.1/2-OE), which occurred in tandem with a reduction of $\mathrm{H} 3.3$ incorporation (Fig 3). The reduced $\mathrm{H} 3.3$ level was more pronounced in the male pronucleus than in the female pronucleus. Although H3.1/2 was only localized to the perinucleolar region of maternal pronuclei in noninjected embryos (Fig 1B), H3.1/2 was also deposited in the perinucleolar region of paternal pronuclei in H3.1/2-OEs (Fig 3). To reduce noise, the embryos were treated with Triton $X-100$ before fixation, which removed any free histones in the nucleoplasm. The structure of the nucleolar precursor body was disrupted after Triton $X$-100 treatment, but an aggregated perinucleolar structure could be identified (Fig S4). Notably, enhanced incorporation of H3.1/2 and reduced incorporation of $\mathrm{H} 3.3$ were detected in Triton $\mathrm{X}-100$ treated H3.1/2-OEs, similarly to embryos that had not been treated with Triton X-100 before fixation (Fig 3). Furthermore, enhanced incorporation of $\mathrm{H} 3.3$ and reduced incorporation of $\mathrm{H} 3.1 / 2$ were observed
A

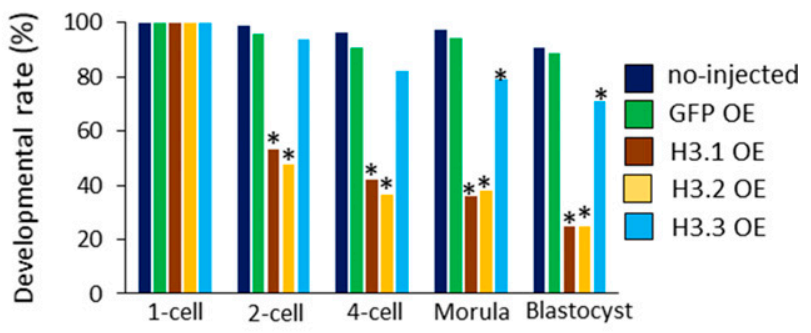

B

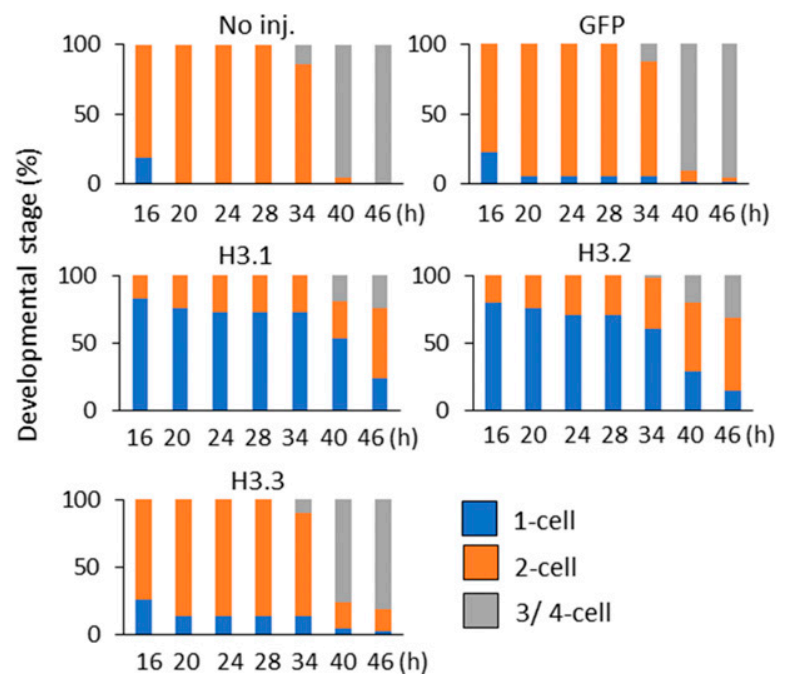

Figure 4. Developmental delay and failure in H3.1/2-overexpressing one-cell embryos.

(A) Developmental rates of noninjected, GFP-, H3.1-, H3.2-, and H3.3-

overexpressing embryos (OEs) during the preimplantation stage. The noninjected, GFP-, H3.1-, H3.2-, and H3.3-OEs were incubated and analyzed at the following times: two-cell (28 h post-insemination [hpi]), four-cell (45-46 hpi), morula (72 hpi), and blastocyst (96 hpi). Eleven independent experiments were performed. For each group, 7-40 embryos were observed for each experiment; 197-228 embryos were observed in total. Asterisks represent statistical significance in the following analyses: for H3.1- and H3.2-OEs, a $x^{2}$ test or Fisher's exact test (when there was a group in which the value was below 5) was performed and the results were considered significant when $P<0.01$ for noninjected, GFP-, and H3.3OEs; for H3.3-OEs, a $X^{2}$ test or Fisher's exact test was performed and the results were considered significant when $P<0.01$ for both noninjected and GFP-OEs. (B) The analysis of developmental stage of noninjected, GFP-, H3.1-, H3.2-, and H3.3-OEs from 16-46 hpi. The developmental rates of noninjected, GFP-, H3.1-, H3.2-, and H3.3-OE were observed at intervals of 4-6 h. Three independent experiments were performed. In each experimental group, 8-27 embryos were observed per experiment; 41-71 embryos were analyzed in total.

in H3.3-overexpressing embryos (H3.3-OEs; Fig S4). These results suggested that the detected histones are deposited in the chromatin, and that an alteration in the chromatin distribution of $\mathrm{H} 3.1 / 2$ and $\mathrm{H} 3.3$ occurs in H3.1/2-OEs.

Next, we investigated the impact of ectopic deposition of H3.1 and $\mathrm{H} 3.2$ at the one-cell stage of preimplantation development. Drastic developmental defects were observed in H3.1/2-OEs (Fig $4 \mathrm{~A}$ ), such that only $50 \%$ of embryos proceeded to the two-cell stage. The detrimental effects of $\mathrm{H} 3.1$ and $\mathrm{H} 3.2$ overexpression were more prominent in blastocysts: only $\sim 30 \%$ of $\mathrm{H} 3.1 / 2-\mathrm{OES}$ reached this stage. These results suggested that the limitation of $\mathrm{H} 3.1 / 2$ nuclear localization at the one-cell stage is essential for preimplantation development. 
Ectopic deposition of $\mathrm{H} 3.1 / .2$ in pronuclei at the one-cell stage delays DNA replication

To gain mechanistic insight into the developmental failure of $\mathrm{H} 3.1$ - and H3.2-OEs, the developmental rates of noninjected, H3.1-, H3.2-, H3.3-, and GFP-OEs were observed at intervals of 4-6 h (Fig 4B). Approximately $80 \%$ of the noninjected, GFP-, and H3.3-overexpressing one-cell embryos had cleaved into two-cell embryos at $20 \mathrm{hpi}$, and into fourcell embryos at 40 hpi. However, more than $70 \%$ of H3.1- and H3.2-OEs had not yet cleaved into two-cell embryos at $20 \mathrm{hpi}$, and most of them remained at the one-cell stage at $34 \mathrm{hpi}$. They initiated cleavage after
$34 \mathrm{hpi}$ and more than $70 \%$ of them developed to two-cell and later stages at $46 \mathrm{hpi}$. After that, some developed to the blastocyst stage, whereas other embryos eventually fragmented (Fig 4A). These results suggest that cellular cleavage from the one-cell stage to the two-cell stage is delayed in H3.1- and H3.2-OEs, which eventually leads to developmental failure.

The delay in cleavage from the one-cell stage to the two-cell stage in H3.1- and H3.2-OEs may be caused by a delay in DNA replication. To address this possibility, we examined the incorporation of BrdU into pronuclei at several time points post-insemination (Fig 5A). In the maternal pronuclei of noninjected, GFP-, and H3.3-OEs,

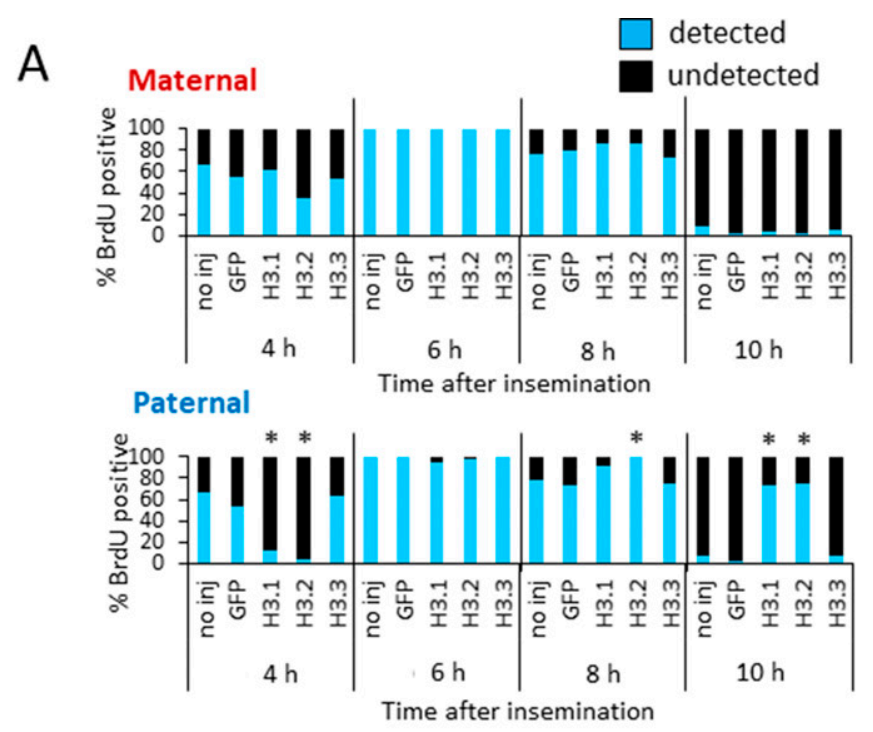

B

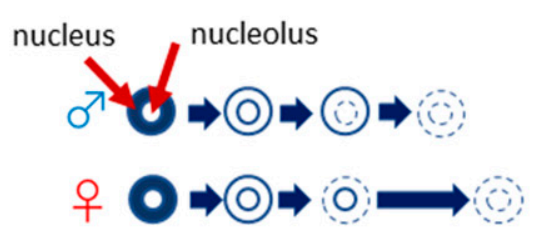

C

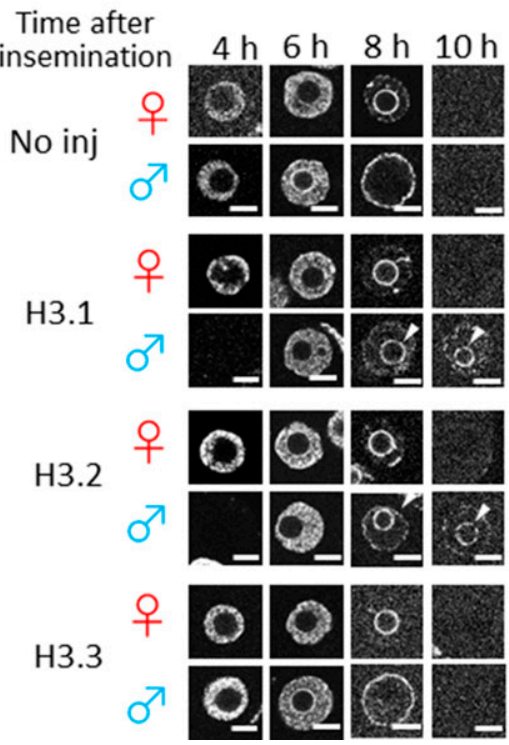

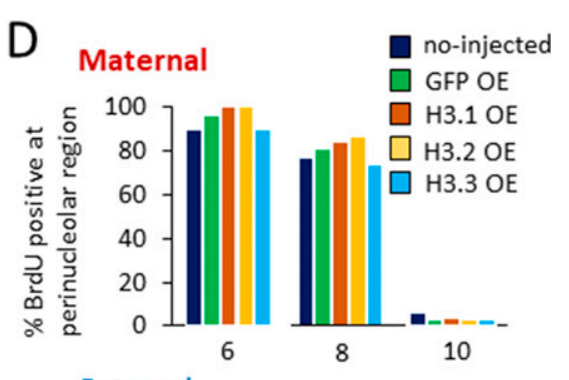

Paternal

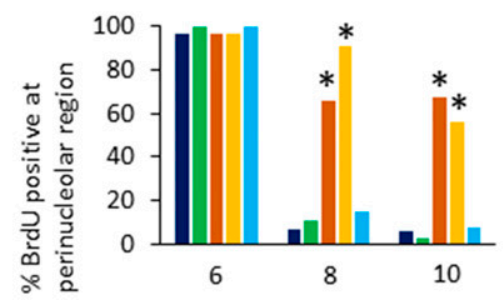

Figure 5. Timing of DNA replication in noninjected, GFP-, H3.1-, H3.2-, and H3.3-overexpressing embryos.

(A) The incorporation of BrdU was analyzed at 4, 6, 8, and $10 \mathrm{~h}$ post-insemination (hpi). Three to five independent experiments were performed. For each injected or noninjected sample, 30-51 embryos were analyzed in total. Asterisks represent statistical significance in the following analyses: for H3.1- and H3.2-overexpressing embryos (OEs), a $x^{2}$ test or Fisher's exact test was performed and the results were considered significant when $P<0.01$ for noninjected, GFP-, and H3.3-OEs; for H3.3-OEs, a $x^{2}$ test or Fisher's exact test (when there was a group in which the value was below 5) was performed and the results were considered significant when $P<0.01$ for noninjected and GFP-OEs. (B) Illustration of asymmetrical DNA replication in paternal and maternal pronuclei in onecell embryos (Aoki \& Schultz, 1999). DNA replication begins in the intranuclear region in both parental pronuclei. In the paternal pronucleus, DNA replication occurs first in the perinucleus, then in the perinucleolar region. In the maternal pronucleus, DNA replication in the perinucleolar region is completed after the paternal pronucleus has completed its replication. (c) Confocal images showing the patterns of BrdU incorporation in maternal ( $(9)$ and paternal ( $\left({ }^{*}\right)$ pronuclei in noninjected, H3.1-, H3.2-, and H3.3-OEs at 4-10 hpi. For each injected or noninjected sample, 30-51 embryos were analyzed. Three to five independent experiments were performed. Representative images are shown for each experiment. Arrowheads indicate the presence of DNA replication at perinucleolar region in the paternal pronuclei of H3.1- and H3.2-OEs at 8-10 hpi. Scale bar, $10 \mu \mathrm{m}$. (D) Bar graph depicting \%BrdU-positive perinucleolar regions for each microinjection condition at 6,8 , and $10 \mathrm{hpi}$. Three to four independent experiments were performed. For each sample, 19-51 embryos were analyzed in total. Asterisks represent the significant differences when compared with noninjected and GFP-OE embryos $\left(P<0.01, \chi^{2}\right.$ test). 
DNA replication had initiated in $>50 \%$ of embryos at 4 hpi. At 10 hpi, DNA replication was complete in most maternal pronuclei of noninjected, GFP-, and H3.3-OEs. Similarly, DNA replication in the maternal pronuclei of H3.1- and H3.2-OEs had initiated at $4 \mathrm{hpi}$ and had been completed by $10 \mathrm{hpi}$. However, in H3.1- and H3.2-OEs, DNA replication was delayed in the paternal pronuclei; $<15 \%$ of the paternal pronuclei had initiated DNA replication at $4 \mathrm{hpi}$, whereas only $25 \%$ had completed DNA replication at $10 \mathrm{hpi}$. These results suggested that the ectopic deposition of H3.1 and H3.2 into one-cell embryo chromatin leads to a delay in DNA replication in the paternal pronucleus, but not the maternal pronucleus.

\section{Ectopic deposition of $\mathrm{H} 3.1$ and $\mathrm{H} 3.2$ delays DNA replication in the perinucleolar region of paternal pronuclei}

In somatic cells, DNA replication is completed earlier in euchromatic regions than in heterochromatic regions (O'Keefe et al, 1992). Previous reports have also shown that DNA replication occurs asynchronously between maternal and paternal pronuclei (Aoki \& Schultz, 1999). In both paternal and maternal pronuclei, DNA replication begins in the nucleoplasm, then continues in the perinuclear and perinucleolar regions. In paternal pronuclei, DNA replication is completed first in the perinucleolar region, then in the perinuclear region; this contrasts with maternal pronuclear DNA replication, which is first completed in the perinuclear region, followed by the perinucleolar region (Fig 5B). Maternal pronuclear DNA replication requires additional time to complete, compared with paternal pronuclear DNA replication. Therefore, the time period required for perinucleolar replication in the female pronucleus determines the timing of S-phase completion.

As shown in Fig 3, the paternal pronuclei of H3.1 and H3.2-OEs displayed H3.1/2 nuclear distributions similar to those of maternal pronuclei. Considering these results, we hypothesized that the delay of DNA replication observed in the paternal pronuclei of $\mathrm{H} 3.1$ and $\mathrm{H} 3.2-$ OEs (Fig 5A) was due to prolonged DNA replication in the perinucleolar region. To test this hypothesis, we observed the DNA replication sequences in maternal and paternal pronuclei at 4, 6, 8, and 10 hpi (Fig 5C). There were no significant differences in the sequence of DNA replication in the maternal pronuclei of noninjected, H3.1-, H3.2-, and H3.3-OEs; in all maternal nuclei, DNA replication occurred in the nucleoplasmic region at 4 and $6 \mathrm{hpi}$, continued in the perinucleolar region at $8 \mathrm{hpi}$, and was completed by $10 \mathrm{hpi}$.

However, the DNA replication pattern differed in the paternal pronuclei of H3.1- and H3.2-OEs; contrary to the noninjected control and $\mathrm{H} 3.3-\mathrm{OEs}$, in which the perinuclear region was replicated last, DNA replication in the paternal perinucleolar region persisted at 10 hpi in H3.1- and H3.2-OEs (Fig 5C and D). We therefore concluded that the slowed cell cycle progression in H3.1- and H3.2-OEs was caused by a delay in DNA replication in the perinucleolar region of the paternal pronucleus. Furthermore, the initiation of DNA replication in the nucleoplasmic region was delayed for $<2 \mathrm{hpi}$ and was completed by $10 \mathrm{hpi}$, whereas DNA replication initiation in the perinucleolar region was delayed for $>4 \mathrm{hpi}$ and persisted at $10 \mathrm{hpi}$; these findings suggested that the delay of DNA replication in the perinucleolar region of the paternal pronucleus is the rate-limiting step, which delays cleavage in H3.1 and H3.2-OEs.
DNA replication in the maternal pronucleus of H3.1- and H3.2-OES was unaffected by the induced incorporation of $\mathrm{H} 3.1$ and $\mathrm{H} 3.2$, which suggests that the maintenance of low H3.1/2 levels in the maternal pronucleus is not required for development. To confirm this suspicion, we generated parthenotes that were devoid of paternal genetic material and examined their developmental capacities when $\mathrm{H} 3.1$ and $\mathrm{H} 3.2$ had been introduced into their chromatin at the one-cell stage. As expected, there were no significant differences in developmental rate between $\mathrm{H} 3.1$ - and H3.2-overexpressing parthenotes and H3.3-overexpressing parthenotes (Fig S5A). H3.1/2 incorporation was verified in H3.2-overexpressing parthenotes; the results indicated that the nuclear localization of $\mathrm{H3.1/2}$ was similar to that of fertilized H3.2-OEs (Fig S5B). This strengthened the hypothesis that H3.1- and H3.2-OEs exhibit delayed cleavage due to $\mathrm{H} 3.1$ and H3.2 deposition in the paternal pronuclei, but not maternal pronuclei. Accordingly, it is essential that levels of $\mathrm{H} 3.1 / 2$ deposition is maintained at a low level in paternal pronuclei because enhancements of $\mathrm{H} 3.1$ and $\mathrm{H} 3.2$ deposition in the perinucleolar region of the paternal pronucleus can delay DNA replication, thereby leading to developmental failure.

\section{Effect of forced nuclear incorporation of H3.1 and H3.2 on epigenetic modifications}

To further elucidate the molecular mechanisms underlying the delay in DNA replication in the paternal pronucleus of H3.1 and H3.2-OEs, we examined histone modification levels. The histone modifications $\mathrm{H} 3 \mathrm{~K} 9 \mathrm{me} 2 / 3$ and $\mathrm{H} 3 \mathrm{~K} 27 \mathrm{me} 3$ are involved in the formation of heterochromatin (Hake et al, 2006); they are often found on H3.1 and H3.2 in various cell types (Hake et al, 2006), and are unevenly detected in the parental pronuclei in one-cell-stage embryos (Lepikhov \& Walter, 2004; Liu et al, 2004; Santos et al, 2005; Puschendorf et al, 2008).

Maternal pronuclear levels of the H3K9me2/3 modification are reportedly higher than the paternal levels (Liu et al, 2004; Lepikhov \& Walter, 2004; Santos et al, 2005:; Puschendorf et al, 2008). Importantly, H3K9me3 was only detected in the maternal perinucleolar region, but not paternal perinucleolar region (Puschendorf et al, 2008). Given that the nuclear distribution of $\mathrm{H3.1/2}$ in the paternal pronuclei became maternal pronucleus-like when H3.1 and H3.2 was overexpressed (Fig 3), we examined the methylation distribution on $\mathrm{H} 3$ variants to explore whether the methylation pattern in paternal pronuclei reflected the pattern in maternal pronuclei. However, the distributions of $\mathrm{H} 3 \mathrm{~K} 9 \mathrm{me} 2$ and $\mathrm{H} 3 \mathrm{~K} 9 \mathrm{me} 3$ modifications in the paternal pronuclei of H3.1- and H3.2-OEs did not differ from the control (Fig 6).

We then examined the distribution of the histone modification $\mathrm{H} 3 \mathrm{~K} 27 \mathrm{me} 3$ in the $\mathrm{H} 3$ overexpression variants. For all overexpression conditions, the H3K27me3 signal was detected throughout the maternal pronucleus (except in the perinucleolar region) and presented a higher overall signal than the paternal pronucleus; however, in paternal pronuclei, H3K27me3 was clearly detected in the perinucleolar region (Fig 6). No differences in H3K27me3 nuclear distribution were observed between H3.1/2-OEs and control embryos.

We originally hypothesized that the H3K27me3 level would decrease in the paternal pronucleus of H3.1- and H3.2-OEs because K27 of H3.3 is methylated by PRC2 in the paternal perinucleolar region (Santenard et al, 2010; Tardat et al, 2015); we also observed a 


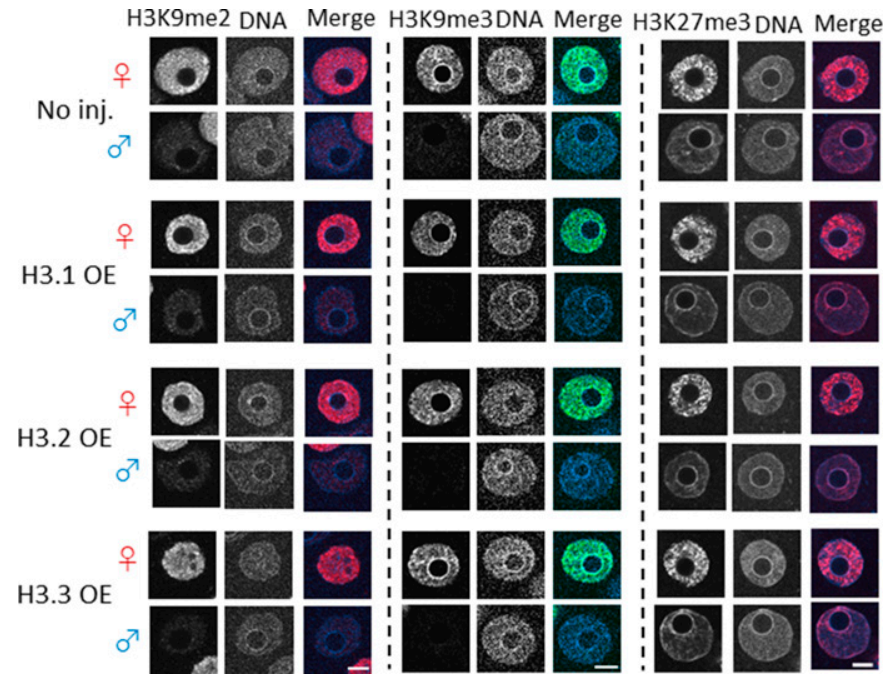

Figure 6. Confocal images showing the effect of forced nuclear incorporation of H3.1, H3.2, and H3.3 on H3K9me2/3 and H3K27me3.

Noninjected, H3.1-, H3.2-, and H3.3-overexpressing (OE) embryos were analyzed for methylation of $\mathrm{H} 3 \mathrm{~K} 9 \mathrm{me} 2, \mathrm{H} 3 \mathrm{~K} 9 \mathrm{me} 3$, and $\mathrm{H} 3 \mathrm{~K} 27 \mathrm{me} 3$ at $11 \mathrm{~h}$ post-insemination. For H3K9me2 immunostaining, three independent experiments were

performed, with the exception of H3.1-overexpressing embryos (two independent experiments). In total, 13-34 embryos were analyzed. For H3K9me3 immunostaining, two independent experiments were performed. 9-14 embryos were observed in total. For H3K27me3 immunostaining, four independent experiments were performed, with the exception of H3.1-overexpressing embryos (three independent experiments); in total, 23-32 embryos were analyzed in each experimental group. Representative images are shown for each experiment. Scale bar, $10 \mu \mathrm{m}$

reduction in $\mathrm{H} 3.3$ levels in the paternal pronucleus in $\mathrm{H} 3.1$ - and H3.2-OEs (Fig 3). However, no reduction in H3K27me3 levels was observed in the perinucleolar region of the paternal pronucleus in H3.1- and H3.2-OES (Fig 6); this suggested that the $\mathrm{H} 3.1 / 2$ that displaced $\mathrm{H} 3.3$ in the paternal pronuclei of H3.1/2-OEs had acquired the K27me3 modification.

\section{Methylation of K27 of H3.1 and H3.2 in paternal perinucleolar chromatin causes developmental failure}

Overexpression of $\mathrm{H} 3.1$ and $\mathrm{H} 3.2$ in one-cell embryos led to enhanced $\mathrm{H} 3.1 / 2$ and reduced $\mathrm{H} 3.3$ in the paternal perinucleolar region, whereas no reduction in H3K27me3 modification was observed (Fig 6). Therefore, we hypothesized that the delay in DNA replication could be caused by the ectopic methylation of $\mathrm{H} 3.1$ and $\mathrm{H} 3.2$ at the K27me3 residue in the paternal perinucleolar region of H3.1/2-OEs. The physiological significance of histone modifications has successfully been probed by microinjection of embryos that contain cRNA encoding $\mathrm{H} 3$ variants with amino acid substitutions (Santenard et al, 2010; Hatanaka et al, 2015; Zhou et al, 2017). To investigate the function of H3K27me3 in paternal pronuclei, we performed microinjection of cRNA encoding H3.1 and H3.2 with an arginine (R) substitution at residue 27 to replace K27 (H3.1K27R and H3.2K27R). The expression and incorporation of the mutant H3 proteins could not be verified directly using an anti-H3.1/2 antibody test, because $\mathrm{K} 27$ is part of the peptide sequence recognized by the antibody. H3.1/2 incorporation into pronuclei was instead verified indirectly through H3.3 displacement; H3.3 decreased in H3.1K27R- and H3.2K27R-microinjected embryos in a manner similar to that observed in H3.1 and H3.2-OEs (Fig 7A). The H3K27me3 level in the perinucleolar region of paternal pronuclei decreased when H3.1K27R and H3.2K27R were overexpressed (Fig 7B).

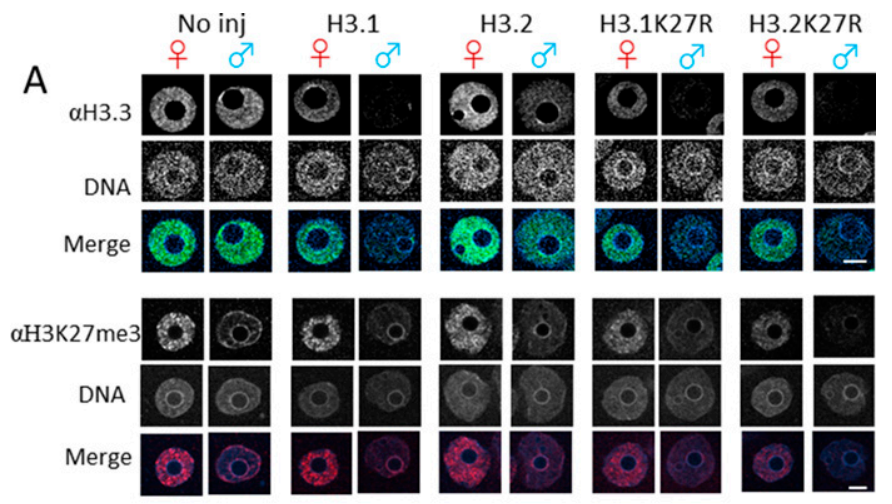

B

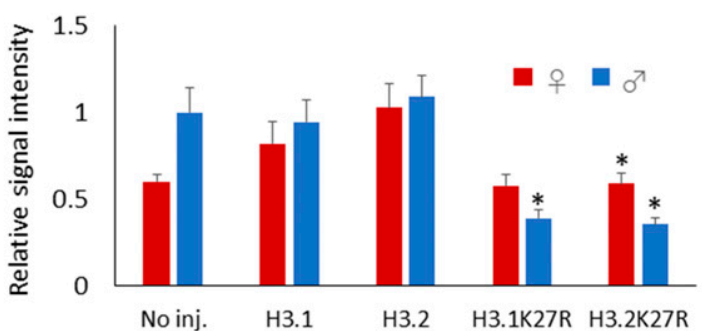

C

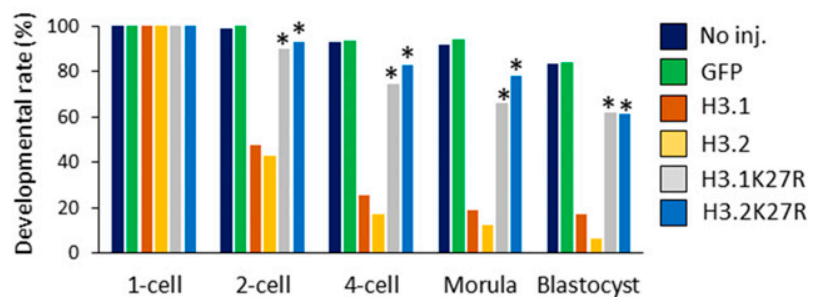

Figure 7. Involvement of $\mathrm{H} 3 \mathrm{~K} 27$ me 3 modification on $\mathrm{H} 3.1 / 2$ in the developmental failure observed in H3.1- and H3.2-overexpressing embryos.

(A) Confocal images of noninjected, H3.1/2-overexpressing, and H3.1/2K27Roverexpressing embryos stained with anti-H3.3 and anti-H3K27me3 antibodies. Three ( $\alpha \mathrm{H} 3.3$ ) or four ( $\alpha \mathrm{H} 3 \mathrm{~K} 27 \mathrm{me} 3)$ independent experiments were performed; 17-25 embryos ( $\alpha \mathrm{H} 3.3$ ) or 37-38 embryos ( $\alpha \mathrm{H} 3 \mathrm{~K} 27 \mathrm{me} 3$ ) were analyzed in each experimental group. Representative images for each experiment are shown. Scale bar, $10 \mu \mathrm{m}$. (B) Bar chart showing the relative signal intensity for detected H3K27me3. H3K27me3 levels in the perinucleolar region were measured in noninjected, H3.1-, H3.2-, H3.1K27R-, and H3.2K27R-overexpressing embryos. Three independent experiments were performed; 27-31 embryos were analyzed in each experimental group. H3K27me3 signal measured at three perinucleolar sites and two background sites was used to quantify the signal intensity of H3K27me3 in the perinucleolar region for each pronucleus. The averaged signal intensity for H3K27me3 of male pronuclei in noninjected embryos was normalized to 1. Bars indicate standard error. Asterisks indicate significant differences in relative H3K27me3 signal intensity between H3.1K27R- or H3.2K27R-overexpressing embryos and H3.1- and H3.2-overexpressing embryos ( $P<0.01, t$ test). (C) Bar graph showing the developmental rates of noninjected, GFP-, H3.1-, H3.2-, H3.1K27R-, and H3.2K27R-overexpressing embryos. Five independent experiments were performed and 98-128 embryos were analyzed in total for each experimental group. Asterisks represent significant differences between developmental rates of H3.1K27R/H3.2K27R-overexpressing embryos and H3.1/ H3.2-overexpressing embryos ( $P<0.01, X^{2}$ test). 
We then examined the developmental rate of the H3.1/2 mutant overexpression lines (Fig 7C). Greater than 90\% of the H3.1K27R and H3.2K27R-OEs progressed to the two-cell stage and $>60 \%$ proceeded to the blastocyst stage, whereas $<50 \%$ of $\mathrm{H} 3.1-$ and $\mathrm{H} 3.2-\mathrm{OEs}$ developed to the two-cell stage and only $20 \%$ proceeded to the blastocyst stage. This strongly suggested that the H3K27me3 modification on H3.1/2 (H3.1/ $2 \mathrm{~K} 27 \mathrm{me} 3$ ) was the determining factor for the delay in DNA replication and subsequent developmental failure. Because K27 is also subjected to acetylation (K27ac) as well as methylation, it would be possible that the absence of K27ac could affect the development. However, this possibility can be excluded because K27ac is originally absent from perinucleolar region in one-cell stage embryos (Fig S6).

\section{Discussion}

In this work, we have demonstrated that the deposition of histone variants in pericentromeric heterochromatin is asymmetrical between the paternal and maternal pronuclei. Moreover, the absence of $\mathrm{H} 3.1$ and $\mathrm{H} 3.2$ in the pericentromeric heterochromatin of the paternal pronucleus, but not maternal pronucleus, is essential for preimplantation development. The ectopic deposition of H3.1 and H3.2 in the paternal pericentromeric heterochromatin caused a delay in DNA replication, resulting in developmental failure. The detrimental effects of H3.1 and H3.2 paternal perinucleolar deposition on development were mitigated when the H3.1/2K27 residue was substituted for $\mathrm{R}$, suggesting that trimethylation of K27 was responsible for the delay in DNA replication.

Epigenetic modifications have recently become the foci of intense academic study, bringing to light asymmetries of modifications between parental pronuclei (Hemberger et al, 2009; Burton \& Torres-Padilla, 2010; Beaujean, 2014; Eckersley-Maslin et al, 2018). However, the biological significance of many such asymmetries has not yet been revealed. For example, the mechanisms regulating the parental asymmetry of global DNA methylation have been well researched, but biological roles for the asymmetries have not yet been established; however, some reports have suggested that these asymmetries are not involved in the regulation of development (Beaujean et al, 2004; Tsukada et al, 2015). In the present study, we propose that, rather than epigenetic modification alone, the combination of $\mathrm{H} 3$ variants and histone modifications (i.e., $\mathrm{H} 3.1 / 2$ with $\mathrm{K} 27 \mathrm{me} 3$ ) determine the differences in DNA replication patterns between parental nuclei.

It was suggested in a previous study that DNA replication in the perinucleolar region of the maternal pronucleus is the rate-limiting step for cleavage from the one-cell stage to the two-cell stage (Aoki \& Schultz, 1999). An investigation of last-replicating DNA regions in syncytial cycles of Drosophila embryos showed that extension of the $\mathrm{S}$ phase occurred as a result of delayed DNA replication in pericentric regions (Shermoen et al, 2010; Su, 2010). This finding suggested that replication of the pericentromeric region is the ratelimiting step for completion of the S phase; furthermore, prolonged replication of the pericentromeric heterochromatin in the paternal pronucleus might lead to delayed cleavage in H3.1 and H3.2-OEs.

It is unclear from our results whether the ectopic deposition of H3.1 and H3.2 led to developmental failure, or whether this failure occurred following reduction in the nuclear deposition of $\mathrm{H} 3.3$ in the H3.1/2-OEs. In previous studies, H3.3 knockdown models caused developmental arrest (Lin et al, 2013); the deletion of HIRA, a chaperone of $\mathrm{H} 3.3$, caused a reduction of DNA replication in both parental pronuclei (Lin et al, 2014). However, the ectopic deposition of H3.1/2 presumably led to developmental failure, because DNA replication in the perinucleolar region was only delayed in the paternal pronucleus (Fig 5), which reflected the pattern of ectopic deposition of $\mathrm{H} 3.1$ and $\mathrm{H} 3.2$ in the same region (Fig 3). One report showed that the depletion of $\mathrm{H} 3.3$ in the paternal pronucleus prevented the incorporation of other core histones or histone variants (H2A and H2A.X) and led to abnormalities in the nuclear envelope and in nuclear transport (Inoue \& Zhang, 2014); it is possible that DNA replication is impeded in abnormally formed pronuclei. However, our H3.1- and H3.2-OEs did not exhibit deformed or undersized pronuclei (Fig 3). Furthermore, Lin et al (2014) showed that the depletion of H3.3 triggered rRNA transcription, and that drug-induced inhibition of rRNA transcription caused cell cycle arrest at the one-cell stage; it did not cause inhibition of DNA replication.

The forced incorporation of H3.1 and H3.2 affected transcription at the one-cell stage. Transcriptional activity was assayed by measurement of embryonic BrU incorporation; this activity was significantly different between the parental pronuclei of H3.2-OE and control embryos, and different between the paternal pronuclei of H3.1-OE and no injected embryos. This activity was significantly different between the paternal pronuclei of H3.1- and H3.2-OEs and the control (Fig S7A). In contrast, no differences were detected between female pronuclei among injection conditions. The reduction in transcriptional activity could not have caused the delay in cleavage into the two-cell stage, as a previous study showed that zygotes treated with transcription-inhibiting $\alpha$-amanitin cleaved to the twocell stage normally (Warner \& Versteegh, 1974). We initially anticipated that the rate of transcription of major satellite repeats would be altered by the forced incorporation of H3.1 and H3.2 in the male pronucleus because major satellite repeats are localized to the pronuclear rim (Probst et al, 2010) and are actively expressed in one-cell-stage embryos (Puschendorf et al, 2008; Probst et al, 2010). However, no significant changes in major satellite expression levels were detected by RT-PCR in H3.1- or H3.2-OES (Fig S7B). Similarly, a recent study showed that ectopic expression of SUV39H1 in one-cell embryos to increase the level of H3K9me3, which generally suppresses transcription in a manner similar to that of H3K27me3, did not affect transcription; however, it had a detrimental effect on preimplantation development (Burton et al, 2020).

We propose the following model, in which the combination of correct $\mathrm{H} 3$ variants and heterochromatin-associated histone modifications is essential for the regulation of preimplantation development; alteration of this combination in the paternal perinucleolar region affected the timing of DNA replication, thus leading to developmental arrest (Fig 8). Immunocytochemical analyses showed that there were no differences in H3K9me2 or me3 levels between H3.1- and H3.2-overexpressing and noninjected control embryos (Fig 6). This finding is supported by a report that H3K9 methyltransferase is not functional in one-cell embryos, whereas there is methylation activity in the oocytes (Liu et al, 2004). Given that newly incorporated H3.1 and H3.2 could not be methylated 


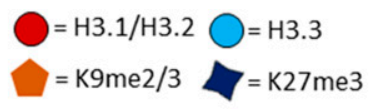

Maternal perinucleolar region

Methyltransferase activity: K9, K27 = not efficiently functional
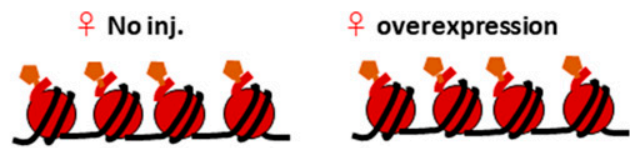

DNA replication:

Slow

Slow,

i.e. no change

Paternal perinucleolar region

Methyltransferase activity: $\mathrm{K} 9$ = not efficiently functional, K27 = ACTIVE

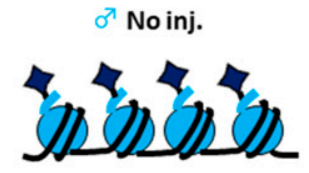

Fast

DNA replication:

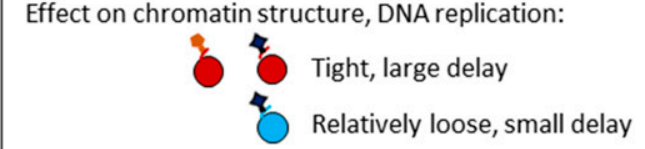

Figure 8. Illustration depicting proposed mechanism for DNA replication delay in the paternal pronucleus of $\mathrm{H3}$.1- or H3.2-overexpressing embryos. In the perinucleolar region, K27 methyltransferase is active only in the paternal pronucleus. Ectopically incorporated $\mathrm{H} 3.1 / 2$ is trimethylated at the $\mathrm{H} 3 \mathrm{~K} 27$ in the paternal pronucleus alone. $\mathrm{H} 3.1 / 2-\mathrm{H} 3 \mathrm{~K} 27 \mathrm{me} 3$ may contribute to the formation of a tight chromatin structure, leading to a delay in DNA replication in the perinucleolar region of the paternal pronucleus. $\mathrm{H} 3.1 / 2$ deposition in the pronuclei of zygotes is limited by reducing mRNA expression and histone incorporation into chromatin.

on $\mathrm{K} 9$ at the one-cell stage, the $\mathrm{H} 3 \mathrm{~K} 9 \mathrm{me} 2 / 3$ levels were unaltered; the only H3K9me2/3 present had been carried over from the oocyte stage (Fig 8). Therefore, the level of K9me2/3-modified H3.1/2 (H3.1/ $2 \mathrm{~K} 9 \mathrm{me} 2 / 3)$ is unchanged in all conditions, and there is no effect on the DNA replication timing in the maternal pronucleus (Fig 8). Similarly, the H3K27me3 level was not altered in the maternal pronuclei of H3.1- and H3.2-OEs (Fig 6) because PRC2 (a protein complex that exhibits H3K27 methyltransferase activity) is inhibited by the presence of HP1 $\beta$ (Burton et al, 2020). It has also been reported that heterochromatin protein $1 \beta$ prevents PRC2 from binding in the maternal perinucleolar region (Tardat et al, 2015). However, PRC2 is functional in the perinucleolar region of the paternal pronucleus. In H3.1- and H3.2-OEs, PRC2 was able to methylate the newly incorporated $\mathrm{H} 3.1$ and $\mathrm{H} 3.2$ that had replaced $\mathrm{H} 3.3$ in the paternal perinucleolar region. Therefore, H3.1/2K27me3 increased in this region. A previous study showed that in one-cell embryos, the H3K27me3 modification was present on $\mathrm{H} 3.3$ in the paternal perinucleolar region (Santenard et al, 2010). H3K27me3 is associated with facultative heterochromatin, whereas H3.3 is mostly associated with euchromatin except for telomeres (Hake et al, 2006; Hake \& Allis, 2006); we therefore hypothesize that H3.3K27me3 forms heterochromatin with a loose structure, relative to H3.1/2K27me3 (Fig 8), although we cannot exclude other possibilities, for example, an effect of chromatin environment on the efficiency of replication origin firing in the repetitive regions and other histone modifications preferring H3.1/H3.2. Our hypothesis is supported by a report that DNA is replicated later in regions with higher levels of H3K27me3 modification in somatic cells (Thurman et al, 2007); in one-cell embryos, DNA in the paternal perinucleolar region (with $\mathrm{H} 3.3 \mathrm{~K} 27 \mathrm{me} 3)$ is replicated before the maternal perinucleolar region (with H3.1/H3.2K9me2/3) (Fig 5C). However, when the newly incorporated $\mathrm{H} 3.1 / 2$ is modified with $\mathrm{K} 27 \mathrm{me} 3$ in the paternal perinucleolar region of $\mathrm{H} 3.1$ - and $\mathrm{H} 3.2-\mathrm{OES}, \mathrm{H} 3.1 / 2 \mathrm{~K} 27$ me3 may promote a tighter and more condensed perinucleolar region, compared with that of noninjected control embryos; this leads to a delay in DNA replication in that region. There are two possible mechanisms by which DNA replication could be delayed: first, the combination of $\mathrm{H} 3.1 / 2$ and K27me3 may have a greater effect on tightening of chromatin structure, compared to H3.1/2K9me2/3; second, the level of K27me3-modified $\mathrm{H3} .1 / 2$ may be greater than that of $\mathrm{K} 9 \mathrm{me} / 3-$ modified H3.1/2, due to the presence of PRC2 activity (Tardat et al, 2015) and the absence of $\mathrm{K} 9$ methylation activity in one-cell embryos (Liu et al, 2004).

The nuclear deposition of $\mathrm{H3.1/2}$ is low at the one-cell stage, relative to the other preimplantation stages. We had originally hypothesized that limited nuclear deposition of $\mathrm{H3} .1 / 2$ at the onecell stage could be caused by low H3.1/2 expression and/or incorporation efficiency into chromatin. The mRNA levels of genes encoding $\mathrm{H} 3.1$ and $\mathrm{H} 3.2$ were lower at the one-cell stage than at other preimplantation stages (Fig 2A). Furthermore, H3.1/2 mRNA levels were lower than H3.3 mRNA levels at the one-cell stage. The efficiency of nuclear incorporation of H3.1 and H3.2 was also lower than that of H3.3 at the one-cell stage (Fig 2B). This low efficiency might have been caused by low expression of CAF1, which is a chaperone of H3.1/2. Our RT-PCR analysis revealed that the transcript level of a CAF1 component, Caf1b, was lower at the one-cell stage than at other preimplantation stages (data not shown). Although the expression levels of H3.1, H3.2, and Caf1b are low in onecell embryos, their transcripts are present at detectable levels. At the one-cell stage, most mRNA transcripts are derived from oocytes, some of which are post-transcriptionally regulated (Yu et al, 2016; Sha et al, 2017); thus, H3.1, H3.2, and/or CAF1b proteins might be expressed at their lowest levels at this stage.

We propose that the localization of H3.1 and H3.2 is limited in one-cell embryos to prevent the detrimental effects elicited by the deposition of these proteins in the paternal pronucleus, thus preventing developmental failure. In the paternal pronucleus, the nuclear localization of $\mathrm{H} 3.1 / \mathrm{H} 3.2$ to the perinucleolar region is equivalent to (or less than) localization to the perinuclear regions. Therefore, DNA replication in the perinucleolar region is completed before replication in the perinuclear region in the paternal pronucleus. In contrast, $\mathrm{H} 3.1 / \mathrm{H} 3.2$ is localized to the perinucleolar region of the maternal pronucleus. Thus, DNA replication in this region is completed last in the maternal pronucleus. The enhanced deposition of H3.1/H3.2 caused the delay in completion of DNA replication in the paternal pronucleus, specifically in the perinucleolar region where pericentromeric heterochromatin is localized. Therefore, in one-cell embryos, this proposed mechanism 
is required to reduce the deposition of $\mathrm{H} 3.1 / \mathrm{H} 3.2$ in the paternal pronucleus by decreasing the overall mRNA expression and the efficiency of chromatin incorporation of H3.1 and H3.2.

\section{Materials and Methods}

\section{Culture condition}

All oocytes and embryos were incubated in droplets of medium covered in mineral oil (Sigma-Aldrich). The samples were incubated with $5 \% \mathrm{CO}_{2}$ at $38^{\circ} \mathrm{C}$.

\section{Collection of preimplantation embryos}

MII-stage oocytes were collected from 3-wk-old BDF1 (DBA2 $\times$ B6Ncr Jms SIc) mice (SLC Japan, Inc.; CLEA Inc.). Mice were injected with six I.U. pregnant mare's serum gonadotropin (ASKA Pharmaceutical Co, Ltd) followed by 7.5 I.U. of human chorionic gonadotropin (ASKA Pharmaceutical Co., Ltd) at 46-50 h after injection of pregnant mare's serum gonadotropin. Oviducts were removed from mice at 14-18 h after human chorionic gonadotropin injection. Mature oocytes surrounded by cumulus cells were collected and placed into $200 \mu \mathrm{l}$ human tubal fluid medium (Quinn \& Begley, 1984) supplemented with $10 \mathrm{mg} / \mathrm{ml} \mathrm{BSA}$ (Sigma-Aldrich). In vitro fertilization was performed to obtain preimplantation embryos by insemination of oocytes with capacitated sperm, which had been preincubated for $2 \mathrm{~h}$. At 3-7 hpi, the embryos and/or unfertilized oocytes were washed in K+-modified simplex optimized medium (KSOM) medium (Lawitts \& Biggers, 1993). Pronuclei were examined at 6-10 hpi and cultured until they reached the blastocyst stage.

In vitro fertilization of denuded oocytes was conducted for microinjection analyses. Capacitated sperm were placed into $50 \mu \mathrm{l}$ human tubal fluid medium (supplemented with BSA) and incubated for 1-2 min. The oocytes were then placed into the same medium. Embryos and/or unfertilized oocytes were washed in KSOM. Embryos at the one-cell, two-cell, four-cell, morula, and blastocyst stages were collected or observed at 10-11, 28-30, 45-46, 72, and 96 hpi, respectively.

All procedures using animals were reviewed and approved by the University of Tokyo Institutional Animal Care and Use Committee (\#C-15-02) and were performed in accordance with the Guiding Principles for the Care and Use of Laboratory Animals.

\section{Immunocytochemistry}

To detect nuclear localization of $\mathrm{H} 3.1 / \mathrm{H} 3.2$ and $\mathrm{H} 3.3$, preimplantation embryos were fixed with 3.7\% PFA and 0.2\% Triton X-100 in PBS for 20 min at room temperature. Oocytes and preimplantation embryos were washed in PBS containing 1\% BSA (BSA/PBS) and incubated overnight with mouse anti-H3.1/H3.2 (1:500; CE-039B; Cosmo Bio) or rat anti-H3.3 (1:100; CE-040B; Cosmo Bio) antibodies in BSA/PBS containing $0.2 \%$ Tween-20. The samples were then washed in BSA/PBS and incubated with Alexa Fluor 488 antimouse or rat IgG secondary antibodies (1:100; Molecular Probes, Invitrogen) for $1 \mathrm{~h}$ at room temperature. The samples were washed in BSA/PBS and mounted on a glass slide with Vectashield mounting media (Vector Laboratories) containing $1.6 \mathrm{ng} / \mu \mathrm{L}$ DAPI. For detection of histones that had been incorporated into chromatin, the procedures described by Hajkova et al (2010) were followed. FLAG-tagged histones were detected using anti-FLAG (1:1,000; SigmaAldrich) and Alexa Fluor 568 anti-rabbit IgG (1:100) antibodies. Endogenous histones were detected using anti-H3.1/H3.2 and anti-H3.3 antibodies with the dilutions described above.

For analysis of histone $\mathrm{H} 3$ dimethylated at lysine 9 (H3K9me2), trimethylated at lysine 27 (H3K27me3) or acetylated at lysine 27 (H3K27ac), the embryos were fixed in 3.7\% PFA/PBS for $1 \mathrm{~h}$ or $20 \mathrm{~min}$, respectively, and permeabilized with $0.5 \%$ Triton $\mathrm{X}-100$ for $15 \mathrm{~min}$. The mouse anti-H3K9me2 (ab1220; Abcam), anti-mouse H3K27me3 (05-851; Upstate/Millipore) and anti-mouse H3K27ac (C15410196; Diagenode) antibodies were diluted 1:100 in 1\% BSA/PBS. For detection of $\mathrm{H} 3 \mathrm{~K} 9 \mathrm{me}$, the embryos were fixed in $3.7 \%$ PFA/PBS containing $0.2 \%$ Triton $\mathrm{X}-100$ for $20-25 \mathrm{~min}$, then incubated with a rabbit anti-H3K9me3 antibody (04-772; Upstate/Millipore) that was diluted 1:100. For secondary antibodies, Alexa Fluor 568 antimouse IgG or Alexa Fluor 488 anti-mouse (Molecular Probes), or fluorescein isothiocyanate-conjugated donkey anti-rabbit (Jackson ImmunoResearch Inc.), were applied; slides were prepared as described above.

The samples were observed under a Carl Zeiss LSM5 exciter laser scanning confocal microscope (Carl Zeiss).

\section{Plasmid construction}

The vector eGFP-polyA pcDNA3.1 (Yamagata et al, 2005) was used to generate Kozak-GFP cRNA as a control for microinjection. This vector was used as the backbone for other constructed vectors. The sequences of H3.1, H3.2, and H3.3 were described by Akiyama et al (2011). The sequences for H3.1K27R and H3.2K27R are as follows:

H3.1K27R: ATGGCTCGTACTAAGCAGACCGCTCGCAAGTCTACCGGCGGCAAGGCCCCGCGCAAGCAGCTGGCCACCAAGGCCGCCCGCAGGAGCGCCCCGGCCACCGGCGGCGTGAAGAAGCCTCACCGCTACCGTCCCGGCACTGTGGCGCTGCGCGAGATCCGGCGCTACCAGAAGTCGACCGAGCTGCTGATCCGCAAGCTGCCGTTCCAGCGCCTGGTGCGCGAGATCGCGCAGGACTTCAAGACCGACCTGCGCTTCCAGAGCTCGGCCGTCATGGCTCTGCAGGAGGCCTGTGAGGCCTACCTCGTGGGTCTGTTTGAGGACACCAACCTGTGCGCCATCCACGCCAAGCGTGTCACCATCATGCCCAAGGACATCCAGCTGGCCCGTCGCATCCGCGGGGAGAGGGCTTAA

H3.2K27R: ATGGCTCGTACGAAGCAGACCGCTCGCAAGTCCACTGGCGGCAAGGCCCCGCGCAAGCAGCTGGCCACCAAGGCCGCCCGCAGGAGCGCCCCGGCCACCGGCGGCGTGAAGAAACCTCACCGCTACCGTCCCGGCACCGTGGCGCTGCGCGAGATCCGGCGCTACCAGAAGTCGACCGAGCTGCTGATCCGCAAGCTGCCGTTCCAGCGCCTGGTGCGCGAGATCGCGCAGGACTTCAAGACCGACCTGCGCTTCCAGAGCTCGGCCGTCATGGCTCTGCAGGAGGCGAGCGAGGCCTACCTTGTGGGTCTGTTTGAGGACACCAACCTGTGCGCCATCCACGCCAAGCGTGTCACCATCATGCCCAAGGACATCCAGCTGGCCCGCCGTATCCGCGGCGAGCGGGCTTAA

\section{cRNA microinjection}

Plasmids were linearized and purified for CRNA generation. In vitro transcription was performed using $T 7$ mMESSAGE mMACHINE kit (Ambion). Mature oocytes were collected in alpha-minimal essential 
medium ( $\alpha$-MEM) (Gibco-BRL) containing 5\% FBS(Sigma-Aldrich) and $10 \mathrm{ng} / \mathrm{ml}$ EGF(Sigma-Aldrich). To remove the cumulus cells, hyaluronidase (Sigma-Aldrich) at a final concentration of $300 \mu \mathrm{g} / \mathrm{ml}$ was added to the medium and incubated for $5 \mathrm{~min}$ at $38^{\circ} \mathrm{C}$ and $5 \%$ $\mathrm{CO}_{2}$. CRNA microinjection into mature oocytes was performed in Hepes-buffered KSOM, using an inverted microscope (Eclipse TE300; Nikon Corporation) with an attached micromanipulator and microinjector (Narishige Co.). cRNA was microinjected into the mature oocytes at a concentration and volume of $100 \mathrm{ng} / \mu \mathrm{l}$ and $10 \mathrm{pl}$, respectively. After microinjection, the oocytes were washed in $\alpha$-MEM (Gibco-BRL) containing 5\% FBS and $10 \mathrm{ng} / \mathrm{ml} \mathrm{EGF}$. The oocytes were microinjected at $1.5-5 \mathrm{~h}$ after oocyte collection and incubated for another $2 \mathrm{~h}$ in $\alpha$-MEM to allow translation of injected histones before in vitro fertilization. The microinjected one-cell embryos were washed in KSOM medium, and then incubated at $38^{\circ} \mathrm{C}$ and $5 \% \mathrm{CO}_{2}$ until they reached the blastocyst stage. The method for in vitro fertilization of denuded oocytes is described above.

\section{Parthenogenesis}

Parthenogenetic embryos were produced in accordance with the procedure described by Kishigami and Wakayama (2007). Mature oocytes were microinjected within $1.5-5 \mathrm{~h}$ after oocyte collection and incubated for another $2 \mathrm{~h}$ to allow translation of histones in $\alpha$-MEM containing 5\% FBS and $10 \mathrm{ng} / \mathrm{ml}$ EGF. The mature oocytes were then activated by incubation for $3 \mathrm{~h}\left(38^{\circ} \mathrm{C}\right.$ with $\left.5 \% \mathrm{CO}_{2}\right)$ in KSOM containing $2 \mathrm{mM} \mathrm{EGTA}, 5 \mathrm{mM} \mathrm{SrCl}_{2}$, and $5 \mu \mathrm{g} / \mathrm{ml}$ Cytochalasin B (Sigma-Aldrich) to generate parthenogenetic embryos with two pronuclei. Parthenogenetic embryos with two pronuclei were produced to generate embryos with the same numbers of histones as the in vitro fertilized embryos. After $3 \mathrm{~h}$ of activation, the embryos were washed with $\mathrm{KSOM}$; parthenogenetic embryos with two pronuclei were selected and cultured in KSOM until the blastocyst stage.

\section{mRNA expression analysis of $\mathrm{H} 3$ variants}

The RPKM values of genes encoding H3.1 (Hist1h3a, Hist1h3g, Hist1h3h, Hist1h3i), H3.2 (Hist1h3f, Hist1h3b, Hist1h3d, Hist1h3e, Hist2h3b, Hist1h3c, Hist2h3c2, and Hist2h3c1), and H3.3 (H3f3a and $\mathrm{H} 3 \mathrm{f} 3 \mathrm{~b}$ ) were obtained from a previously published RNA-seq dataset (Abe et al, 2015). RPKM values for each H3 variant were totaled to compare total expression levels among the variants. The expression level of $\mathrm{H} 3.3$ at the one-cell stage was normalized to 1 and the relative expression levels of $\mathrm{H} 3.1, \mathrm{H} 3.2$ for one-cell to blastocyst stages, and H3.3 for two-cell to blastocyst were calculated; expression ratios were calculated for $\mathrm{H} 3.1$ and $\mathrm{H} 3.2$.

\section{Immunofluorescence quantification}

The signal intensities of FLAG and H3K27me3 antibodies, as well as DAPI, were quantified using ImageJ software (National Institutes of Health). The signal intensities of FLAG of the pronuclei were subtracted by the average of two background areas in the cytoplasm, then corrected using the DAPI signal. The signal intensities of H3K27me3 at the perinucleolar region were calculated by quantifying three areas of perinucleolar regions (in which the average signal of two background areas in the cytoplasm was subtracted) and then corrected using the DAPI signal of these regions. The maternal and paternal pronuclei were identified by their size and proximity to the second polar body; the maternal pronucleus is smaller and proximal to the polar body.

\section{BrdU incorporation assay for DNA replication}

DNA replication was analyzed by examination of BrdU incorporation in one-cell embryos at 4, 6, 8, and 10 hpi. BrdU (Roche) was added to the $\mathrm{KSOM}$ to a final concentration of $10 \mu \mathrm{M}$. After incubation at $38^{\circ} \mathrm{C}$ for $30 \mathrm{~min}$, the embryos were washed three times in 1\% BSA/PBS and fixed with $3.7 \%$ PFA/PBS for $1 \mathrm{~h}$ at room temperature. After fixation, the samples were washed with $1 \%$ BSA/PBS three times, then washed three times in PBS containing 0.05\% Tween-20. The samples were then placed under $2 \mathrm{~N} \mathrm{HCl}$ containing $0.1 \%$ Triton $\mathrm{X}-100$ for $1 \mathrm{~h}$ at $37^{\circ} \mathrm{C}$. Next, the samples were washed with $1 \% \mathrm{BSA} /$ PBS three times and transferred into $0.1 \mathrm{M}$ Tris- $\mathrm{HCl}(\mathrm{pH} 8.5) / \mathrm{PBS}$ containing $0.02 \%$ Triton $\mathrm{X}-100$ for $15 \mathrm{~min}$ at room temperature. The samples were washed three times with 1\% BSA/PBS and incubated overnight with primary antibodies: mouse anti-BrdU (1:100; Roche) and rabbit anti-H3K9me3 (1:1,000; Upstate/Millipore). Alexa Fluor 647 anti-mouse IgG (Molecular Probes) and fluorescein isothiocyanate-conjugated donkey anti-rabbit (Jackson ImmunoResearch Inc.) were used as secondary antibodies; slides were prepared as described above.

\section{In vitro transcription assay}

Total transcriptional activity was evaluated by the incorporation of BrUTP into nascent mRNA, as described previously (Kim et al, 2002). BrU signal intensity was quantified using Image) software (National Institutes of Health), following the same method as FLAG quantification.

\section{RT-PCR}

H3.1-, H3.2-, H3.3-, and GFP-overexpressing embryos and noninjected embryos were placed in ISOGEN RNA extraction reagent (Nippon Gene); RNA extraction was conducted in accordance with the manufacturer's instructions. The extracted RNA was reverse transcribed using the PrimeScript RT-PCR Kit (TaKaRa). Real-time PCR was conducted as described by Kawamura et al (2012). Primers used to detect major satellite repeats were as described by Inoue et al (2012).

\section{Inhibition of DNA replication}

DNA replication was inhibited by transferring one-cell embryos to KSOM supplemented with $3 \mu \mathrm{g} / \mathrm{ml}$ aphidicolin (Sigma-Aldrich) at $15 \mathrm{hpi}$ and collected for sampling at $26 \mathrm{hpi}$. DMSO was used as the solvent for aphidicolin suspension; control embryos were cultured with DMSO.

\section{Supplementary Information}

Supplementary Information is available at https://doi.org/10.26508/lsa. 202101102. 


\section{Acknowledgements}

We thank Tetsuya Kojima and Shoji Oda for their helpful discussions. This work was supported in part by Grants-in-Aid (to F Aoki) from the Ministry of Education, Culture, Sports, Science and Technology of Japan (\#20062002, \#25252054, 16H01215, 18H03970, and 19H05752).

\section{Author Contributions}

M Kawamura: conceptualization, data curation, formal analysis, investigation, and visualization, methodology.

S Funaya: data curation, formal analysis, investigation, and methodology. K Sugie: data curation, formal analysis, and methodology.

MG Suzuki: data curation and investigation.

F Aoki: conceptualization, data curation, formal analysis, funding acquisition, validation, visualization, and project administration.

\section{Conflict of Interest Statement}

We declare that there is no conflict of interest that could be perceived as prejudicing the impartiality of the research reported.

\section{References}

Abe K, Yamamoto R, Franke V, Cao M, Suzuki Y, Suzuki MG, Vlahovicek K, Svoboda P, Schultz RM, Aoki F (2015) The first murine zygotic transcription is promiscuous and uncoupled from splicing and $3^{\prime}$ processing. EMBO / 34: 1523-1537. doi:10.15252/embj.201490648

Akiyama T, Suzuki O, Matsuda J, Aoki F (2011) Dynamic replacement of histone H3 variants reprograms epigenetic marks in early mouse embryos. PLoS Genet 7: e1002279. doi:10.1371/journal.pgen.1002279

Aoki E, Schultz RM (1999) DNA replication in the 1-cell mouse embryo: Stimulatory effect of histone acetylation. Zygote 7: 165-172. doi:10.1017/s0967199499000532

Beaujean N, Hartshorne G, Cavilla J, Taylor J, Gardner J, Wilmut I, Meehan R, Young L (2004) Non-conservation of mammalian preimplantation methylation dynamics. Curr Biol 14: R266-R267. doi:10.1016/ j.cub.2004.03.019

Beaujean N (2014) Histone post-translational modifications in preimplantation mouse embryos and their role in nuclear architecture. Mol Reprod Dev 81: 100-112. doi:10.1002/mrd.22268

Burton A, Brochard V, Galan C, Ruiz-Morales ER, Rovira Q, Rodriguez-Terrones D, Kruse K, Le Gras S, Udayakumar VS, Chin HG, et al (2020) Heterochromatin establishment during early mammalian development is regulated by pericentromeric RNA and characterized by non-repressive H3K9me3. Nat Cell Biol 22: 767-778. doi:10.1038/ s41556-020-0536-6

Burton A, Torres-Padilla ME (2010) Epigenetic reprogramming and development: A unique heterochromatin organization in the preimplantation mouse embryo. Brief Funct Genomics 9: 444-454. doi:10.1093/bfgp/elq027

Campos El, Reinberg D (2009) Histones: Annotating chromatin. Annu Rev Genet 43: 559-599. doi:10.1146/annurev.genet.032608.103928

Eckersley-Maslin MA, Alda-Catalinas C, Reik W (2018) Dynamics of the epigenetic landscape during the maternal-to-zygotic transition. Nat Rev Mol Cell Biol 19: 436-450. doi:10.1038/s41580-018-0008-z

Ferreira J, Carmo-Fonseca M (1997) Genome replication in early mouse embryos follows a defined temporal and spatial order. J Cell Sci 110: 889-897. doi:10.1242/jcs.110.7.889
Hajkova P, Jeffries SJ, Lee C, Miller N, Jackson SP, Surani MA (2010) Genomewide reprogramming in the mouse germ line entails the base excision repair pathway. Science 329: 78-82. doi:10.1126/science.1187945

Hake SB, Allis CD (2006) Histone H3 variants and their potential role in indexing mammalian genomes: The "H3 barcode hypothesis". Proc Natl Acad Sci U S A 103: 6428-6435. doi:10.1073/pnas.0600803103

Hake SB, Garcia BA, Duncan EM, Kauer M, Dellaire G, Shabanowitz J, BazettJones DP, Allis CD, Hunt DF (2006) Expression patterns and posttranslational modifications associated with mammalian histone $\mathrm{H} 3$ variants. J Biol Chem 281: 559-568. doi:10.1074/jbc.M509266200

Hatanaka Y, Inoue K, Oikawa M, Kamimura S, Ogonuki N, Kodama EN, Ohkawa Y, Tsukada Y, Ogura A (2015) Histone chaperone CAF-1 mediates repressive histone modifications to protect preimplantation mouse embryos from endogenous retrotransposons. Proc Natl Acad Sci U S A 112: 14641-14646. doi:10.1073/pnas. 1512775112

Hemberger M, Dean W, Reik W (2009) Epigenetic dynamics of stem cells and cell lineage commitment: Digging Waddington's canal. Nat Rev Mol Cell Biol 10: 526-537. doi:10.1038/nrm2727

Inoue A, Matoba S, Zhang Y (2012) Transcriptional activation of transposable elements in mouse zygotes is independent of Tet3-mediated 5methylcytosine oxidation. Cell Res 22: 1640-1649. doi:10.1038/ cr.2012.160

Inoue A, Zhang Y (2014) Nucleosome assembly is required for nuclear pore complex assembly in mouse zygotes. Nat Struct Mol Biol 21: 609-616. doi:10.1038/nsmb.2839

Kawamura M, Akiyama T, Tsukamoto S, Suzuki MG, Aoki F (2012) The expression and nuclear deposition of histone $\mathrm{H} 3.1$ in murine oocytes and preimplantation embryos. / Reprod Dev 58: 557-562. doi:10.1262/ jrd.2012-074

Kim JM, Ogura A, Nagata M, Aoki F (2002) Analysis of the mechanism for chromatin remodeling in embryos reconstructed by somatic nuclear transfer. Biol Reprod 67: 760-766. doi:10.1095/biolreprod.101.000612

Kishigami S, Wakayama T (2007) Efficient strontium-induced activation of mouse oocytes in standard culture media by chelating calcium. J Reprod Dev 53: 1207-1215. doi:10.1262/jrd.19067

Lawitts JA, Biggers JD (1993) Culture of preimplantation embryos. Methods Enzymol 225: 153-164. doi:10.1016/0076-6879(93)25012-q

Lepikhov K, Walter J (2004) Differential dynamics of histone H3 methylation at positions $\mathrm{K} 4$ and $\mathrm{K} 9$ in the mouse zygote. BMC Dev Biol 4: 12. doi:10.1186/1471-213X-4-12

Lin CJ, Conti M, Ramalho-Santos M (2013) Histone variant H3.3 maintains a decondensed chromatin state essential for mouse preimplantation development. Development 140: 3624-3634. doi:10.1242/dev.095513

Lin CJ, Koh FM, Wong P, Conti M, Ramalho-Santos M (2014) Hira-mediated H3.3 incorporation is required for DNA replication and ribosomal RNA transcription in the mouse zygote. Dev Cell 30: 268-279. doi:10.1016/ j.devcel.2014.06.022

Liu H, Kim JM, Aoki F (2004) Regulation of histone H3 lysine 9 methylation in oocytes and early pre-implantation embryos. Development 131: 2269-2280. doi:10.1242/dev.01116

Liu Z, Tardat M, Gill ME, Royo H, Thierry R, Ozonov EA, Peters AH (2020) SUMOylated PRC1 controls histone H3.3 deposition and genome integrity of embryonic heterochromatin. EMBO J 39: e103697. doi:10.15252/embj.2019103697

Martin C, Beaujean N, Brochard V, Audouard C, Zink D, Debey P (2006) Genome restructuring in mouse embryos during reprogramming and early development. Dev Biol 292: 317-332. doi:10.1016/j.ydbio.2006.01.009

O'Keefe RT, Henderson SC, Spector DL (1992) Dynamic organization of DNA replication in mammalian cell nuclei: Spatially and temporally defined replication of chromosome-specific alpha-satellite DNA sequences. I Cell Biol 116: 1095-1110. doi:10.1083/jcb.116.5.1095 
Probst AV, Almouzni G (2011) Heterochromatin establishment in the context of genome-wide epigenetic reprogramming. Trends Genet 27: 177-185. doi:10.1016/j.tig.2011.02.002

Probst AV, Okamoto I, Casanova M, El Marjou F, Le Baccon P, Almouzni G (2010) A strand-specific burst in transcription of pericentric satellites is required for chromocenter formation and early mouse development. Dev Cell 19: 625-638. doi:10.1016/j.devcel.2010.09.002

Probst AV, Santos F, Reik W, Almouzni G, Dean W (2007) Structural differences in centromeric heterochromatin are spatially reconciled on fertilisation in the mouse zygote. Chromosoma 116: 403-415. doi:10.1007/s00412-007-0106-8

Puschendorf M, Terranova R, Boutsma E, Mao X, Isono K, Brykczynska U, Kolb C, Otte AP, Koseki H, Orkin SH, et al (2008) PRC1 and Suv39h specify parental asymmetry at constitutive heterochromatin in early mouse embryos. Nat Genet 40: 411-420. doi:10.1038/ng.99

Quinn P, Begley AJ (1984) Effect of human seminal plasma and mouse accessory gland extracts on mouse fertilization in vitro. Aust J Biol Sci 37: 147-152. doi:10.1071/bi9840147

Rapkin LM, Ahmed K, Dulev S, Li R, Kimura H, Ishov AM, Bazett-Jones DP (2015) The histone chaperone DAXX maintains the structural organization of heterochromatin domains. Epigenetics Chromatin 8: 44. doi:10.1186/ s13072-015-0036-2

Saksouk N, Simboeck E, Déjardin J (2015) Constitutive heterochromatin formation and transcription in mammals. Epigenetics Chromatin 8: 3. doi:10.1186/1756-8935-8-3

Santenard A, Ziegler-Birling C, Koch M, Tora L, Bannister AJ, Torres-Padilla ME (2010) Heterochromatin formation in the mouse embryo requires critical residues of the histone variant H3.3. Nat Cell Biol 12: 853-862. doi:10.1038/ncb2089

Santos F, Peters AH, Otte AP, Reik W, Dean W (2005) Dynamic chromatin modifications characterise the first cell cycle in mouse embryos. Dev Biol 280: 225-236. doi:10.1016/j.ydbio.2005.01.025

Sha QQ, Dai XX, Dang Y, Tang F, Liu J, Zhang YL, Fan HY (2017) A MAPK cascade couples maternal mRNA translation and degradation to meiotic cell cycle progression in mouse oocytes. Development 144: 452-463. doi:10.1242/dev.144410

Shermoen AW, McCleland ML, O'Farrell PH (2010) Developmental control of late replication and S phase length. Curr Biol 20: 2067-2077. doi:10.1016/j.cub.2010.10.021

Su TT (2010) Heterochromatin replication: Better late than ever. Curr Biol 20: R1018-R1020. doi:10.1016/j.cub.2010.11.003

Tagami H, Ray-Gallet D, Almouzni G, Nakatani Y (2004) Histone H3.1 and H3.3 complexes mediate nucleosome assembly pathways dependent or independent of DNA synthesis. Cell 116: 51-61. doi:10.1016/s00928674(03)01064-X

Tang MC, Jacobs SA, Mattiske DM, Soh YM, Graham AN, Tran A, Lim SL, Hudson DF, Kalitsis P, O'Bryan MK, et al (2015) Contribution of the two genes encoding histone variant h3.3 to viability and fertility in mice. PLoS Genet 11: e1004964. doi:10.1371/journal.pgen.1004964
Tardat M, Albert M, Kunzmann R, Liu Z, Kaustov L, Thierry R, Duan S, Brykczynska U, Arrowsmith CH, Peters AH (2015) Cbx2 targets PRC1 to constitutive heterochromatin in mouse zygotes in a parent-of-origindependent manner. Mol Cell 58: 157-171. doi:10.1016/j.molcel. 2015.02.013

Thurman RE, Day N, Noble WS, Stamatoyannopoulos JA (2007) Identification of higher-order functional domains in the human ENCODE regions. Genome Res 17: 917-927. doi:10.1101/gr.6081407

Torres-Padilla ME, Bannister AJ, Hurd PJ, Kouzarides T, Zernicka-Goetz M (2006) Dynamic distribution of the replacement histone variant $\mathrm{H} 3.3$ in the mouse oocyte and preimplantation embryos. Int I Dev Biol 50: 455-461. doi:10.1387/ijdb.052073mt

Tsukada Y, Akiyama T, Nakayama KI (2015) Maternal TET3 is dispensable for embryonic development but is required for neonatal growth. Sci Rep 5: 15876. doi:10.1038/srep15876

Wang ZF, Krasikov T, Frey MR, Wang J, Matera AG, Marzluff WF (1996a) Characterization of the mouse histone gene cluster on chromosome 13: 45 histone genes in three patches spread over 1Mb. Genome Res 6: 688-701. doi:10.1101/gr.6.8.688

Wang ZF, Tisovec R, Debry RW, Frey MR, Matera AG, Marzluff WF (1996b) Characterization of the 55-kb mouse histone gene cluster on chromosome 3. Genome Res 6: 702-714. doi:10.1101/gr.6.8.702

Warner CM, Versteegh LR (1974) In vivo and in vitro effect of alpha-amanitin on preimplantation mouse embryo RNA polymerase. Nature 248: 678-680. doi:10.1038/248678a0

Yamagata K, Yamazaki T, Yamashita M, Hara Y, Ogonuki N, Ogura A (2005) Noninvasive visualization of molecular events in the mammalian zygote. Genesis 43: 71-79. doi:10.1002/gene.20158

Yu C, Ji SY, Sha QQ, Dang Y, Zhou JJ, Zhang YL, Liu Y, Wang ZW, Hu B, Sun QY, et al (2016) BTG4 is a meiotic cell cycle-coupled maternal-zygotictransition licensing factor in oocytes. Nat Struct Mol Biol 23: 387-394. doi:10.1038/nsmb.3204

Yukawa M, Akiyama T, Franke V, Mise N, Isagawa T, Suzuki Y, Suzuki MG, Vlahovicek K, Abe K, Aburatani H, et al (2014) Genome-wide analysis of the chromatin composition of histone $\mathrm{H} 2 \mathrm{~A}$ and $\mathrm{H} 3$ variants in mouse embryonic stem cells. PLoS One 9: e92689. doi:10.1371/ journal.pone.0092689

Zhou L, Baibakov B, Canagarajah B, Xiong B, Dean I (2017) Genetic mosaics and time-lapse imaging identify functions of histone $\mathrm{H} 3.3$ residues in mouse oocytes and embryos. Development 144: 519-528. doi:10.1242/ dev.141390

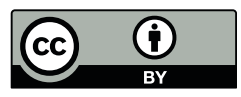

License: This article is available under a Creative Commons License (Attribution 4.0 International, as described at https://creativecommons.org/ licenses/by/4.0/). 